\title{
IL-10 Cytokine as Potential Biomarkers in Women with Fibromyalgia Who Underwent to a Short Balneotherapy Treatment
}

Angela Maria Brol ${ }^{1}$

https://orcid.org/0000-0001-9809-9835

Valéria Zardo ${ }^{1}$

https://orcid.org/0000-0002-4797-0544

Rafael Barbieri ${ }^{2}$

https://orcid.org/0000-0003-4194-4588

\section{Fernanda Barbisan ${ }^{3}$}

https://orcid.org/0000-0002-2960-7047

Ivana Beatrice Manica $\mathrm{Cruz}^{3}$

https://orcid.org/0000-0003-3008-6899
Gerson Azulim Müller ${ }^{4}$

https://orcid.org/0000-0003-0342-4733

\author{
Adarly Kroth ${ }^{1}$ \\ https://orcid.org/0000-0002-4079-9684
}

Antuani Rafael Baptistella ${ }^{1}$

https://orcid.org/0000-0003-1708-9921

\section{Geisson Marcos Nardi ${ }^{5}$}

https://orcid.org/0000-0003-0484-8490

Glauber Wagner, 6

https://orcid.org/0000-0001-5003-6595

1 University of West Santa Catarina, Graduate Program of Bioscences and Heath, Joaçaba, Santa Catarina, Brazil; ${ }^{2}$ Rheumatology Clinic, Concórdia, Santa Catarina, Brazil; ${ }^{3}$ Farroupilha Federal Institute of Education Science and Technology, Panambi, Rio Grande do Sul, Brazil; ${ }^{4}$ Federal University of Santa Maria, Laboratory of Biogenomics; ${ }^{5}$ Federal University of Santa Catarina, Departament of Morphology, Florianópolis, Santa Catarina, Brazil; ${ }^{6}$ Federal University of Santa Catarina, Departament of Microbiology, Immunology and Parasitology, Florianópolis, Santa Catarina, Brazil.

Received: 2018.12.12; Accepted: 2020.04.24.

*Correspondence: glauber.wagner@ufsc.br; Tel.: ++55 4935512000 (G.W.)

\section{HIGHLIGHTS}

- Balneotherapy reduced pain and improve clinical conditions in patients with FM

- Balneotherapy increased the IL-10 and decreased pro-inflammatory cytokines

- PGAM-I expression indicates that enzyme could not be useful as a biomarker in FM

Abstract: Fibromyalgia (FM) is a nonarticular rheumatic syndrome that leads to diffuse myalgia, sleep disturbances and morning stiffness. Balneotherapy has been shown an effective strategy to improve the health conditions of patients; however, the treatment follow-up is based on patient report due to the lack of biomarkers. Thus, this study evaluated the application of cytokines and phosphoglycerate mutase I (PGAMI) to monitoring FM patient underwent to balneotherapy treatment. Eleven healthy and eleven women with FM were submitted to daily sessions of balneotherapy during 10 days. Clinical and quality of life parameters were assessed through a FIQ questionnaire. Blood levels of TNF- $\alpha$, interleukins (IL-1, IL-2 and IL-10) and PGAM-I expression in patients' saliva were also evaluated. Patients with FM showed significant improvements in their clinical status after treatment. Also, FM patients has IL-10 levels lower than healthy women and the balneotherapy increased the expression of this cytokine in both groups, concomitantly to pain relief. Although inflammatory cytokines (IL-1, IL-2 and TNF- $\alpha$ ) were more expressed in FM patients than healthy patients their levels did not reduce after treatment. A slight increase of PGAM-I expression was 
observed. In conclusion, IL-10 levels could be a useful biomarker to balneotherapy follow-up of FM patients. However, these findings must be analyzed in a larger number of patients in order to validate IL-10 as an effective biomarker.

Keywords: Fibromyalgia; balneotherapy; biomarkers; physical activity; cytokines.

\section{INTRODUCTION}

Rheumatic diseases are responsible for physical, psychological and social problems in patients who develop such pathologies, so it is relevant to use multidimensional assessment measures with regard to the quality of life of these patients. Fibromyalgia (FM) is a non-articular rheumatic disease of unknown etiology. It is characterized by a polymorph clinical condition that includes diffuse myalgia, sleep disorders, morning stiffness and psychological disorders such as depression and anxiety, pain is the main symptom reported and studied in this pathological condition [1-3]. FM is more prevalent in women than in men, and its diagnosis is remains largely clinical, since there are no additional tests able to identify it [4-8].

Isolated drug therapy has not been effective in the treatment of FM [9]. However, balneotherapy demonstrates to be an effective alternative for the improvement of the clinical condition of patients due to possible changes in the expression of inflammatory mediators [10-13]. However, the subjectivity of the FM symptoms associated with the lack of markers for its pathophysiological mechanisms turns the diagnosis and treatment of patients into a major challenge for health professionals [14].

Thus, the identification of potential biomarkers that can be used to aid the diagnosis and monitoring the FM treatment is important. Among these, the most prominent are serological biomarkers (as antibodies, neuropeptides, inflammatory markers), pro-inflammatory and anti-inflammatory cytokines, proteins differentially expressed in patients with $\mathrm{FM}$, as cyclophilin A, phosphoglycerate mutase I (PGAM-I) and calgranulins (A and C) [15-16].

PGAM-I was reported highly expressed in patients with FM than in healthy individuals [16]. PGAM-I is the eighth enzyme of glycolysis metabolism responsible for the reversible catalysis of 3-phosphoglycerate into 2-phosphoglycerate [18]. Since FM is a disease that causes an increase in the oxidative stress, this protein might be involved in the limitation of oxygen to biological tissues [4].

Although FM is not classified as an inflammatory disease, there are reports demonstrating changes in the levels of pro- and anti-inflammatory cytokines, especially proteins involved in the communication between the immune and nervous systems [1-2,4-5]. Pro-inflammatory cytokines such as interleukins (IL-1 and IL-2) and interferon gamma (IFN- $\gamma$ ) induce the inflammatory response, stimulate cytotoxic cells and recruit macrophages, while anti-inflammatory cytokines such as IL-4 and IL-10 are expressed after recruitment of macrophages [12] and have the role to attenuate the inflammatory process in rheumatic disease [6-8].

Lactate dehydrogenase (LDH) is another FM related enzyme and it is an important enzyme in the metabolism of carbohydrates, showing its high serum levels whenever there is any tissue damage. Studies suggest that FM patients show high levels of LDH when compared to healthy individuals even at rest, generating muscle lactic acid build-up and consequent myalgia [19-20].

Therefore, this study sought to evaluate the variation of the possible marker PGAM-I in the saliva of women with FM who underwent intervention by balneotherapy. In addition, variations were assessed in the expression of inflammatory markers such as alpha tumor necrosis factor (TNF- $\alpha$ ), cytokines IL-1, IL-2 and IL-10 and LDH enzyme, as well as the evolution of the clinical condition of FM patients undergoing this treatment.

\section{MATERIAL AND METHODS}

\section{Ethical aspects and clinical evaluation of patients}

All procedures performed in studies involving human participants were in accordance with the ethical standards of the institutional and/or national research committee and with the 1964 Helsinki declaration and its later amendments or comparable ethical standards and the CNS 466/2012 from National Health Council, Ministry of Health, Brazil. Thus project was approved by the Ethics Committee of the University of West Santa Catarina (Approval number 916.872). A total of $11(n=11)$ patients with previous diagnosis of FM were preselected for this study, considering the following inclusion criteria: (i) be female, (ii) provide positive rheumatologic diagnosis for FM (according to the criteria established by the American College of Rheumatology) [6-7], (iii) not have a diagnosis of associated diseases, (iv) not practice regular physical 
activity and (vi) have been diagnosed by the same rheumatologist. Also, a control group (CG) composed by 11 women $(n=11)$ without diagnosis of $F M$, of similar age and not practicing any regular physical activity was selected. For both groups, information on age, occupation, education or use or not of drugs was collected. The FM group received the "Fibromyalgia Impact Questionnaire (FIQ)" [18] to get to know the clinical aspects related to the pathology before and after the physical therapy intervention. On this questionnaire, the frequency of execution of the main activities of daily living (ADLs) was evaluated, such as shopping, cooking, cleaning the house, driving a car or riding a bus. Based on the ADLs, the functional capacity (FC) of the patients was evaluated.

\section{Physical therapy intervention}

The physical therapy intervention was performed by balneotherapy, consisting of 10 hydrokinesiotherapy sessions in hot water with an average temperature of $37^{\circ} \mathrm{C}$, with five weekly subsections of 50 minutes each, for a period of two consecutive weeks, according to the adapted protocol of Silva and coauthors [21]. The treatment protocol consisted in four stages: 1) global warm-up by walking the length of the pool straight and forth for 10 minutes; 2) stretching the main muscle groups of the upper limbs (UL), lower limbs (LL), trunk and neck for 10 minutes; 3) light aerobic exercises and muscle strengthening, initially conducted without external load and progressing to exercises with use of accessories and water weights for 20 minutes; 4) relaxation with stretching and breathing exercises for 10 minutes. FM and control groups received the same physical therapy interventions, by the same professional physiotherapist, at the same time.

\section{Collection of biological material}

Saliva and blood were used as biological material to assess the levels of protein and inflammatory markers of the groups, respectively. Biological materials were collected before the beginning of the balneotherapy treatment and after the end of the 10th subsection of the balneotherapy treatment. For the evaluation of PGAM-I, 1-3 mL of unstimulated saliva was collected from each patient in both groups in sterile tubes in the morning (between 6:00 and 7:00 a.m.) before any intake. Saliva samples were kept at $-20^{\circ} \mathrm{C}$ for protein extraction and evaluation of the expression PGAM-I. To assess inflammatory markers (TNF- $\alpha$, IL-1, IL-2 and IL-10) $20 \mathrm{~mL}$ of peripheral venous blood were collected from each individual, also in the early morning. The blood samples were kept at $4{ }^{\circ} \mathrm{C}$ for 1 hour and centrifuged at $5.000 \mathrm{xg}$ for 15 minutes. The serum obtained from the supernatant was stored at $-80^{\circ} \mathrm{C}$ for the analyses.

\section{Proteins extraction}

Soluble proteins were obtained by TCA-acetone precipitation. Briefly, samples were submitted to centrifugation in $14.000 \mathrm{xg}$ for $30 \mathrm{~min}$ at $4{ }^{\circ} \mathrm{C}$ to remove cell debris. The supernatant was precipitated with $10 \%$ of trichloroacetic acid (TCA) (Sigma-Aldrich) in acetone for one hour at $-20{ }^{\circ} \mathrm{C}$. Then the solution was centrifuged by $14.000 \mathrm{xg}$ for 15 minutes at $4^{\circ} \mathrm{C}$ and the precipitate was washed three times in $100 \%$ acetone in the same conditions. The final precipitate was dried at room temperature for 10 minutes. Proteins were solubilized in a solubilization buffer (2 mM SDS, $22 \%$ glycerol, $100 \mathrm{mM}$ Tris- $\mathrm{HCl}, \mathrm{pH} 6.8,1 \mathrm{mM}$ of protease inhibitors cocktail (Sigma-Aldrich $\AA$ ) and were quantified using the Bradford reagent (Bio-Rad®) and reading at a wavelength of $595 \mathrm{~nm}$. Subsequently samples were stored at $-80^{\circ} \mathrm{C}$.

\section{Evaluation of PGAM I expression}

Soluble proteins of the volunteer's saliva were solved again in 1\% SDS-PAGE. Briefly, $25 \mu \mathrm{g}$ of total protein were solubilized in a running buffer $2 \times$ (SDS 10\% $2 \mathrm{~mL}$; 2-mercaptoethanol $500 \mu \mathrm{L}$; glycerol $2 \mathrm{~mL}$; $2 \%$ bromophenol blue $400 \mu \mathrm{L} ; 0.5 \%$ Tris- $\mathrm{HCl} \mathrm{pH} \mathrm{6.8,} 2.5 \mathrm{~mL}$; MilliQ water $10 \mathrm{~mL}$ ), heated for 5 minutes at $95{ }^{\circ} \mathrm{C}$ and settled for 2 hours under $40 \mathrm{~mA}$. For Western Blotting (WB), proteins were transferred to nitrocellulose membranes (GE Healthcare Bio-Sciences $\AA$ ) in a transfer buffer (25 mM Tris, 192 mM Glycine, $20 \%$ Methanol) for 16 hours at $25 \mathrm{~V}$ and then stained with Ponceau (Ponceau-S $0.1 \%$ in $10 \%$ acetic acid). Subsequently, membranes were blocked in a PBS-Tween 20 solution $(0.1 \%)$ containing $5 \%$ of skimmed powder milk at $4{ }^{\circ} \mathrm{C}$ for 12 hours. After five washing cycles in a cleaning solution (PBS-Tween $200.1 \%$ ), membranes were incubated for 90 minutes at $37^{\circ} \mathrm{C}$ with human anti-PGAM I antibody (Santa Cruz Biotechnology $\AA$ ) diluted in 1:2.5 in dilute solution (PBS with $2.5 \%$ of skimmed powder milk). Then, membranes were washed again and incubated for 60 minutes under stirring with anti-lgG peroxidase conjugate (Santa Cruz Biotechnology $\AA$ ) diluted in 1:5.000 in dilution solution. After another series of washes, the development was performed by chemiluminescence using an ECL kit (Amersham®) and after 5 minutes 
of exposure to radiographic hyperfilm (Amersham $\AA$ ) they were immediately developed with development reagents $($ Kodak $\AA)$. Then, the protein PGAM-I expression was evaluated based on densitometry of bands using the ImageJ program. The pixel values were normalized using sum of the pixels of correspondent sample lane of the nitrocellulose membrane and the results of the PGAM expression were expressed in arbitrary unit (u.a.).

\section{Quantification of the plasma markers}

The variation of LDH enzyme, C-reactive protein (CRP), cytokines TNF- $\alpha$, IL-1, IL-2 and IL-10 was performed from the blood serum (diluted in 1:2 and 1:4) of the individuals in both groups, before and after intervention. The quantification of the LDH enzyme was performed by a chemical kinetic method using the lactate dehydrogenase kit LDH UV (Bioclin®), the C-reactive protein (CRP) was measured by an immunoturbidimetric test (Bioclin $\circledast$ ), and the cytokines IL-1, IL-2, IL-10 and TNF-a were quantified by enzyme immunoassay using the Quantikine kit (R\&D Systems ${ }^{\circledR}$ ), according to the manufacturer's recommendations. The $\mathrm{LDH}$ results are expressed in $\mathrm{mg} / \mathrm{mL}$, the CRP quantity in $\mathrm{mg} / \mathrm{dL}$ and the cytokines quantity in $\mathrm{pg} / \mathrm{mL}$.

\section{Statistical analysis}

The comparison between the frequencies of socio-demographic data was performed using nonparametric test of $X 2$ Pearson's. For statistical analysis of $F I Q$, the responses were normalized on a $0-10$ scale, according to Marques and coauthors [22], which compares the FIQ means before and after the intervention through the paired t-Student's test 22. To assess the variation of the protein PGAM-I expression by WB the One-way analysis of variance (ANOVA) test was applied, being followed by the post-hoc Bonferroni's Multiple Comparison test. The paired t-Student's test was used for the variations in levels of cytokines and LDH between the groups. For all methods statistically significant differences were considered when $p$-values were $<0.05$. Statistical analyzes were performed using the GraphPad Prism® software Version 6.0.

\section{RESULTS}

\section{Balneotherapy improved clinical and physical aspects, but not psychological aspects in the FM group}

The sociodemographic characteristics of the patients in the FM and control groups were evaluated during the anamnesis (Table 1). The age of both groups was similar, as well as the level of education. Most women with FM were farmers, while in the control group most of them were merchants. Mostly, patients from the FM group are beneficiaries of the Brazilian National Institute of Social Services (INSS), reporting an average time for assistance of 5.1 years. Also, patients from the control group were taking diuretic and antihypertensive drugs, as the women of the FM group reported the use of diuretics and antihypertensives, antidepressants, anxiolytics, muscle relaxants and anti-inflammatory drugs. 
Table 1. Sociodemographic data evaluated in patients of the FM and the control group.

\begin{tabular}{|c|c|c|}
\hline Sociodemographic aspects & FM Group (n=11) & Control Group (n=11) \\
\hline \multicolumn{3}{|c|}{ Average age (years) $^{*}$} \\
\hline \multicolumn{3}{|c|}{ Educational Level (\%) ${ }^{*}$} \\
\hline Incomplete Elementary School & 54.5 & 36.4 \\
\hline Elementary School Concluded & 18.2 & 36.4 \\
\hline High School Concluded & 27.3 & 27.2 \\
\hline \multicolumn{3}{|c|}{ Professional Occupation (\%) } \\
\hline Merchant & 18.2 & 45.4 \\
\hline Housekeeper & 0.0 & 27.2 \\
\hline Dressmaker & 0.0 & 9.1 \\
\hline Housewife & 18.2 & 9.1 \\
\hline Farmer & 36.4 & 0.0 \\
\hline Retired & $\begin{array}{r}27.2 \\
\text { Other data }\end{array}$ & 9.1 \\
\hline Receives Social Security Benefits & 90.9 & 9.1 \\
\hline Use of Continuing Medication* & 100.0 & 45.4 \\
\hline
\end{tabular}

Results are presented in percentage. ${ }^{*} \mathrm{p} \leq 0.007$

About clinical and physical evolution of the groups, there were significant improvements after treatment in the FM group (Table 2). It was observed that $31.4 \%$ of patients reported being well seven days after treatment and that there was a $30 \%$ reduction in the number of days that these women reported they were unable to work due to the symptoms generated by the FM. Regarding the pain, $63.6 \%$ of the patients reported feeling much pain in the assessment before the intervention, but only $9.09 \%$ of them reported feeling only "a little" pain at the end of the intervention. Another important factor is that $63.6 \%$ of women reported not showing morning stiffness after the end of the intervention. The psychic symptoms assessed, anxiety and depression, showed no variation at the end of the intervention. The main daily living activities (ADL) reported by patients with FM after intervention were shopping, cooking, cleaning the house, driving a car or riding a bus.

The control group did not present significant variation in the FIQ score (data no show). Although the questionnaire presented in its composition parameters of life quality, it is specific for patients with fibromyalgia. Therefore, we assume that the absence of significant results from the control group in the FIQ score demonstrates the validity of the questionnaire in evaluating patients with fibromyalgia.

Table 2. Clinical, physical and psychological evolution of patients with FM.

\begin{tabular}{lccc}
\hline & Before treatment $^{\mathbf{a}}$ & After treatment $^{\mathbf{a}}$ & $\boldsymbol{p}$-value \\
\hline Functional Capacity (CF) & $0.47(0.27-0.77)$ & $0.3(0.03-0.63)$ & $p=0.0001$ \\
Score & $1(0-7)$ & $5(0-7)$ & $p=0.0027$ \\
Feel good (days) & $4(0-7)$ & $2(0-4)$ & $p=0.0049$ \\
Missing work (days) & $1(0.67-1.00)$ & $0.67(0.33-1.00)$ & \\
Work ability & $1(0.67-1.00)$ & $0.67(0.67-1.00)$ & \\
Pain & $0.67(0.67-1.00)$ & $0.67(0.33-1.00)$ & \\
Fatigue & $0.67(0.33-1.00)$ & $0.33(0.33-0.67)$ & \\
Wake up tired & $0.67(0.33-1.00)$ & $0.33(0.33-0.67)$ & \\
Stiffness & $0.67(0.67-1.00)$ & $0.67(0.33-1.00)$ & \\
Anxiety & $0.67(0.33-1.00)$ & $0.67(0.33-1.00)$ & \\
Depression & $6.75(5.30-8.23)$ & $5.44(3.89-6.96)$ & $p=0.0001$ \\
\hline FIQ Score & & &
\end{tabular}

a Values: Median (Minimum - Maximum) 


\section{Balneotherapy has no influence in PGAM-I expression}

The median values of PGAM-I expression were calculated and compared before and after physical therapy interventions in both groups. Despite the expression of PGAM-I in individuals of the FM group and the control group after treatment being similar, having no statistical differences, before treatment this protein was slightly more expressed in the control group than in the FM group. In addition, the expression of PGAMI increased by 1.1 times in the FM group after treatment when compared to the previous expression to the treatment and to the control group, which had a reduction of 1.2 times (Figure 1).

(a)

\section{PGAM I}

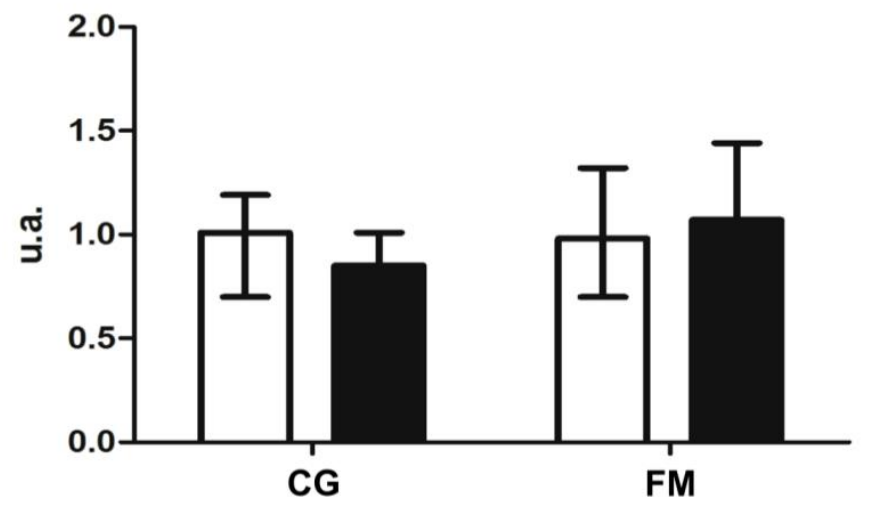

(b)

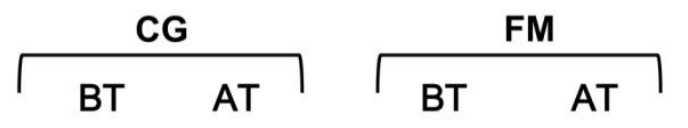

(c)

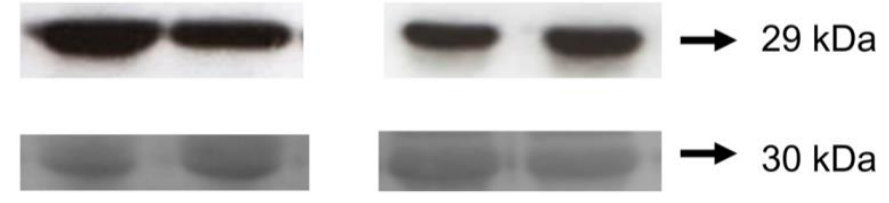

Figure 1. Protein PGAM I expression (29 kDa) assessed by Western Blotting using anti-PGAM I monoclonal antibody. (a) Bands densitometry: graph showing the median and the range (u.a.) observed in the control group (CG) and patients with FM (FM) before (BT) and after (AT) physical therapy; (b) Representative Western Blotting identifying the region of 29 kDa (PGAM I) recognized by anti-PGAM I monoclonal antibody (1/1.000); (c) 30 kDa region of nitrocellulose membrane as example of the normalization of the amount of protein. For the WB we used $30 \mu \mathrm{g}$ of total protein extract derived from the saliva of the individuals. Arbitrary units (u.a.); Open bar: before balneotherapy; Closed bar: After balneotherapy.

\section{FM patients has higher levels of LDH than control group}

Regarding the level of LDH, both the FM group and the control group had a slight decrease in the levels of this enzyme after treatment (Figure 2), but this reduction was significant only in the control group $(p=0.0239)$. It was also observed that the level of LDH in patients with FM is higher than in the control group individuals, both before and after the treatment (Figure 2). 


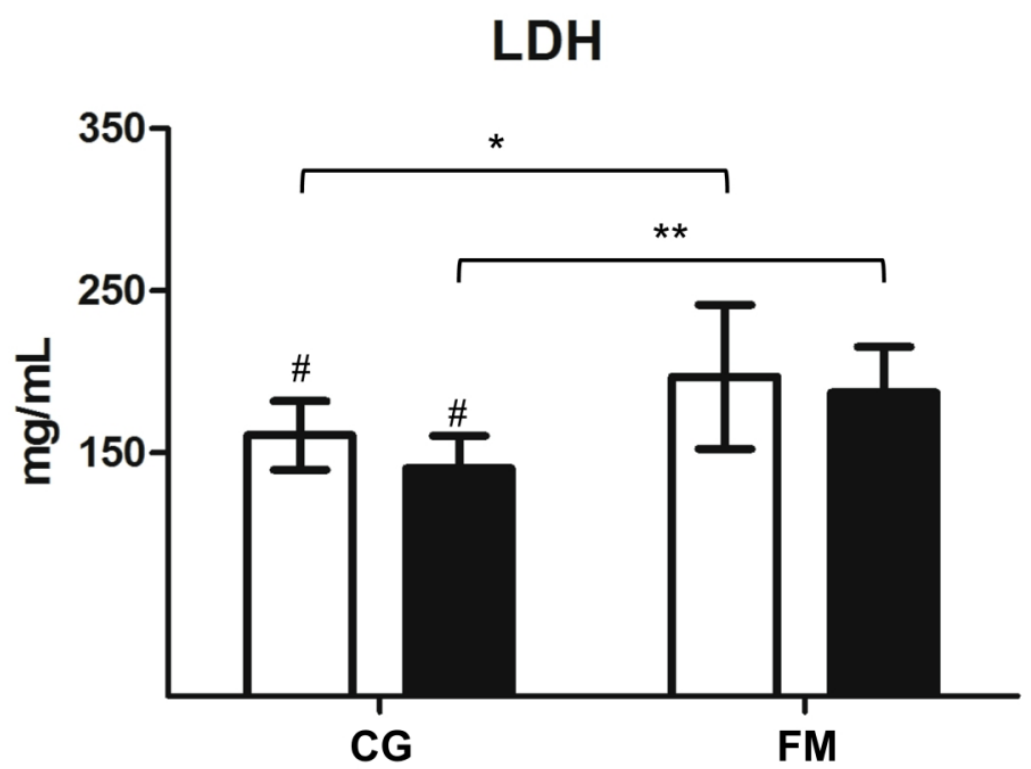

Figure 2. Quantification of serum LDH levels of control group (CG) patients and group of patients with fibromyalgia (FM). The graph shows the median in $\mathrm{mg} / \mathrm{mL}$ of the 11 samples analyzed for each group before and after physical therapy. Significant decrease in the LDH levels after treatment $(\# p=0.0239)$. Significance differences between groups before $\left({ }^{*} \mathrm{p}=0.0243\right)$ and after treatment $\left({ }^{* *} \mathrm{p}=0.0002\right)$. Open bar: before balneotherapy; Closed bar: After balneotherapy.

\section{Balneotherapy Increases the anti-inflammatory cytokine IL-10 levels but has no interference in the pro-Inflammatory levels}

After quantification of the serum levels of IL-1, IL-2, TNF- $\alpha$ and IL-10 of individuals of both groups before and after treatment (Figure 3), was observed that although there is a trend of reduction in the levels of proinflammatory cytokines IL-1, IL-2 and TNF- $\alpha$ in the FM group, this reduction was not significant $(p>0.05)$. However, there was a significant increase in the levels of anti-inflammatory cytokine IL-10 after treatment in both groups. We can also point out that patients with FM have higher levels of pro-inflammatory cytokines (IL-1, IL-2 and TNF- $\alpha$ ) and lower levels of anti-inflammatory cytokine IL-10 when compared to the control group (CG), both, before and after treatment. The CRP levels were lower than the reference value $(6 \mathrm{mg} / \mathrm{dL})$ in all individuals in both groups, in this way determined as nonreactive and without quantitative values. 
(a)

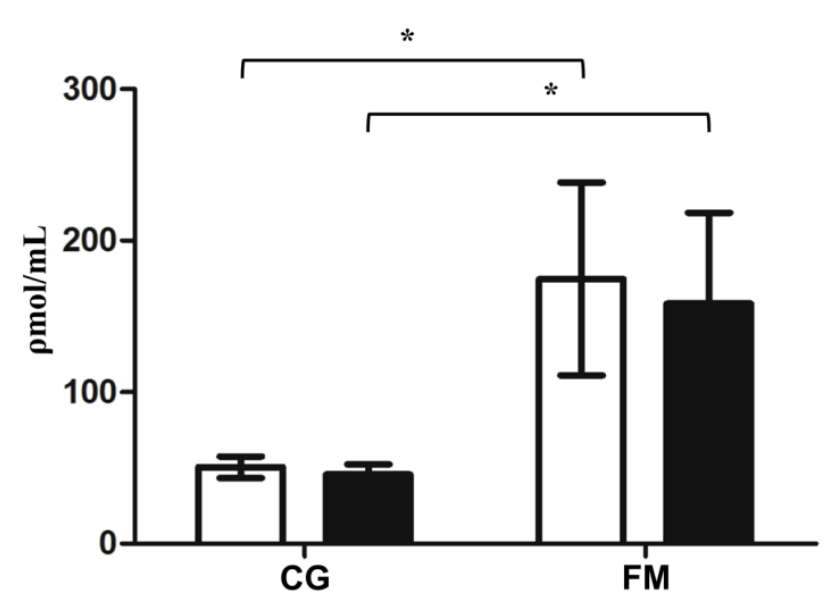

(c)

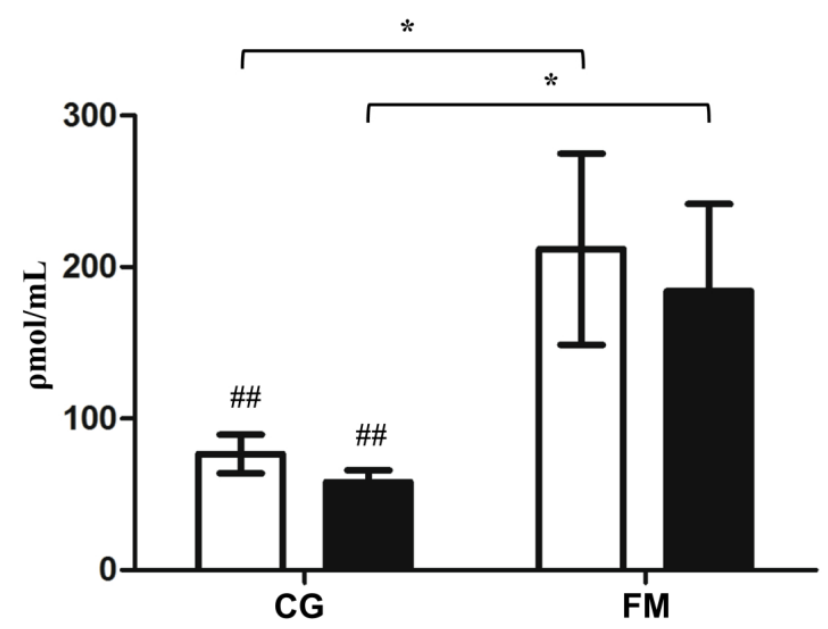

(b) IL-2

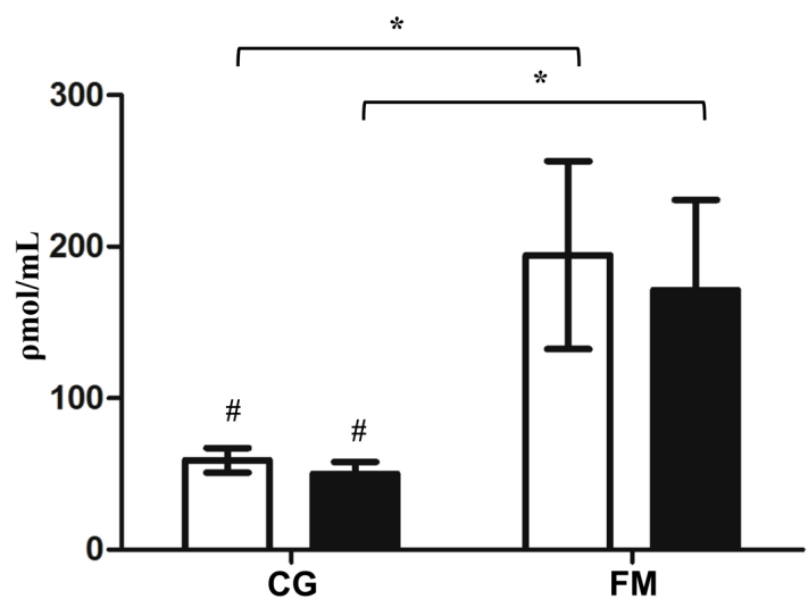

(d)

IL-10

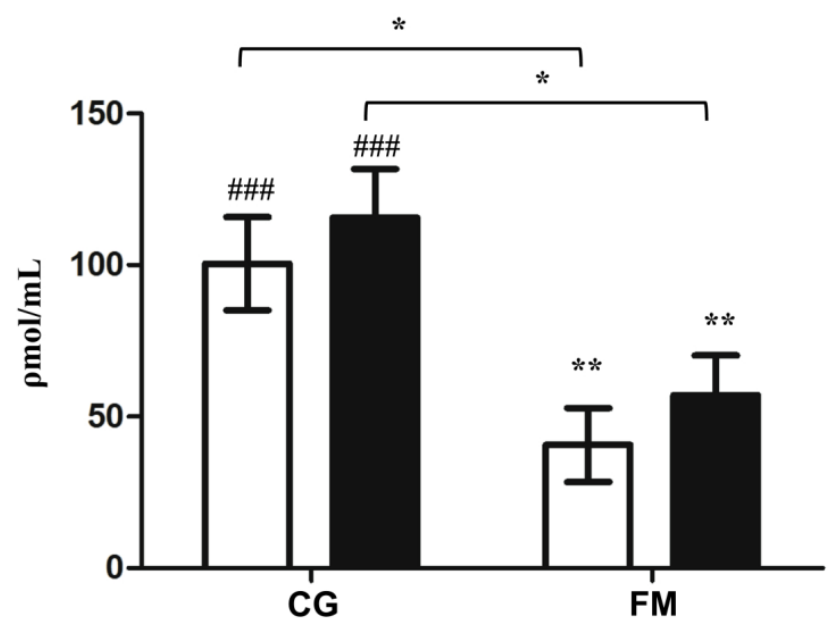

Figure 3. Serum levels of IL-1 (a), IL-2 (b), TNF- $\alpha$ (c) and IL-10 (d) of patients from both groups before and after the physical therapy quantified by enzyme immunoassay using the Quantikine ${ }^{\circledR}$ kit (R\&D Systems). Significant statistical values: ${ }^{*} \mathrm{p}=0.0001 ;{ }^{*} \mathrm{p}=0.0150 ;{ }^{*} \mathrm{p}=0.0006$; ${ }^{\# \#} \mathrm{p}=0.0063$ and ${ }^{* *} \mathrm{p}=0.00332$. Open bar: before balneotherapy; Closed bar: After balneotherapy.

\section{DISCUSSION}

As an alternative to the treatment of fibromyalgia, balneotherapy is described as effective in reducing and alleviating pain, increasing functional capabilities of individuals and consequently improving quality of life [23]. Based on the FIQ results, the treated patients who underwent balneotherapy for 10 days showed significant improvements in quality of life, pain relief and increased everyday activities. Although the results confirm the efficacy of this treatment for this disease, as reported in the literature [22], the assessment of the quality of life of patients with FM in the clinical routine does not use biomarkers as parameters to evaluate the improvement of the condition of these patients.

Patients with FM had the same age and education similar to the patients in the control group, however, was observed a difference in the professional activities, with most part of FM patients reporting to be farmers (beneficiaries of Social Security), and most part of patients in the control group reporting to be merchants. Activities that require too much physical effort and repeatability of movements, such as farming, housework and others, may compromise musculoskeletal structures, often leading to depressive conditions for labor incapacity [24]. In this study, we have also observed depression conditions in patients with FM, which justifies the continuing use of antidepressants and anxiolytics. This fact is common in patients with FM, according to Kaplan and coauthors [25] and Neumann and coauthors [26] depressive symptoms occur in these patients due to the FM chronicity, leading to the need of medication to treat depression.

The identification of FM using biomarkers has been presented as a strategy for the diagnosis, as well as monitoring treatments of patients with FM [15]. Among these biomarkers, there is the search for antibodies, 
neuropeptides, inflammatory markers, pro-inflammatory and anti-inflammatory cytokines, and proteins like cyclophilin A, PGAM-I and calgranulins (A and C) [15-16].

This study assessed the variation of the PGAM-I expression in the saliva of women with FM and inflammatory serum markers such as TNF-a, IL-1, IL-2 and IL-10 cytokines and LDH enzyme. These parameters were evaluated before and after physiotherapy treatment through balneotherapy. The use of saliva as biological material is promising in the search for biomarkers of diseases, since this is a non-invasive method of collection, reducing the discomfort and anxiety of the patient [27].

The results described herein show that PGAM-I was similarly expressed in individuals from both groups, but the expression of PGAM-I was slightly increased by 1.1 times in the FM group after treatment compared with the previous expression to treatment and in the control group this expression reduced by 1.2 times. Bazzichi and coauthors [16] detected PGAM-I at high levels in women with FM as compared to the healthy population using 2-D proteomic approaches. In the present study, we demonstrated that the level of PGAMI in saliva before balneotherapy is similar in both groups ( $C G$ and $F M$ ) which was expected since these groups are paired, i.e. composed by sedentary individuals. These data are different from those described by Bazzichi and coauthors [16], however these authors did not describe whether the groups are composed by individuals paired for physical activity, which may be explain the lower levels of PGAM-I in the control group than in the FM group.

Bazzichi and coauthors [16] showed a reduction in the expression of this enzyme in patients with FM treated for 15 days (two weeks) with mud bath and balneotherapy in Italy. In this study, we did not observe a reduction in the PGAM-I levels after the balneotherapy in patients with $\mathrm{FM}$, possibly because the resistance to exercise in patient with FM [28] required a longer treatment period in order to reduce the level of PGAM-I in saliva, as observed by Bazzichi and coauthors [16].

Biochemically, PGAM-I is an enzyme presents at the end of the glycolytic pathway, it has an increased expression in aerobic conditions, and it also has the role to convert 3-phosphoglycerate to 2phosphoglycerate, which is a fundamental phase for the formation of pyruvate and entry in Krebs cycle, and physiologically, the deficiency in just 5\% in PGAM-I activity in the muscles leads to fatigue, contractures and other myalgia during extreme exercise [29-30]. The increased activity of PGAM-I tends to reduce the formation of lactate mediated by $\mathrm{LDH}$, thereby reducing the muscle lactic acid build-up to assist in reducing muscle pains [30], which has been observed in this study. Patients with FM have higher levels of LDH than in the control group (Figure 2), but only a slight reduction in LDH levels has been observed after treatment in the control group.

These combined data do not rule out the use of PGAM-I present in the saliva of FM patients as a potential biomarker for monitoring the improvement in FM patients through balneotherapy, because there has been an increasing trend in the levels of this enzyme after only 10 days of treatment and, in case of a prolonged treatment, this variation might be more significant. However, in the treatment conditions used in this study, the evaluation of PGAM-I did not show significant changes, only in increasing trends.

With respect to inflammatory markers, although the FM is not an inflammatory disease, disorders of cytokine have been reported in the literature [1-2,4-5,31]. Studies suggest that cytokines may play a role in both, the etiology and intensity of FM symptoms, suggesting that these molecules are important in the communication between the immune and nervous systems [9-11].

In this study, serum levels of pro-inflammatory cytokines (IL-1, IL-2 and TNF- $\alpha$ ) were high before the balneotherapy in patients with FM, even in patients who were being administered anti-inflammatories in comparison to the levels of patients in the control group (Figure 3). Interestingly these cytokines did not have a significant reduction in the FM group after treatment with balneotherapy, only IL-2 had a significant reduction in individuals of the control group after treatment. The anti-inflammatory cytokine IL-10 was found with higher levels in the control group comparing to patients with FM. Moreover, an increased expression of anti-inflammatory cytokine IL-10 became evident in both groups after being submitted to balneotherapy (Figure 3d). These results corroborate the results presented by Wallace and coauthors [32] suggesting that $\mathrm{IL}-10$ increasing is an important factor in blocking pain because it helps in reducing the levels of proinflammatory cytokines, which may be responsible for pain. Cytokines are mediators necessary to perform the inflammatory response, and the anti-inflammatory cytokines such as IL-10 may minimize the infection and its undesirable effects [33]. IL-10 is described as a suppressor of pro-inflammatory cytokines, being reported for prevention of graft rejection and for the treatment of sepsis, rheumatoid arthritis and psoriasis [34].

Therefore, this study shows that balneotherapy increased the IL-10 levels, which contributes to decreased levels of pro-inflammatory cytokines in FM patients, reduction of pain reported by patients with FM and consequently the improvement of the quality of life of these patients. 


\section{CONCLUSIONS}

Patients with FM who underwent balneotherapy for 10 days reported improvements in the clinical conditions and in the performance of activities of daily living, concomitantly with an increase in IL-10 expression in patients with FM indicating a decrease in pain in these individuals. Also, the slight variation in the protein PGAM-I expression indicates that this enzyme could not be useful as a biomarker for monitoring short period of fibromyalgia therapy. Moreover, quantifying the IL-10 serum levels may also be a parameter for clinical monitoring of patients with FM. However, these findings must be analyzed in a larger number of patients in order to validate IL-10 as an effective biomarker.

Funding: This work was funded by Fundação de Amparo à Pesquisa e Inovação do Estado de Santa Catarina - Fapesc and Conselho Nacional de Desenvolvimento Científico e Tecnológico - CNPq

Acknowledgments: This study was supported by Unoesc trough the institutional FAPE program (2015). AMB, VZ and FB were recipients of Santa Catarina Universities Support Fund for Maintenance and Development of Higher Education (UNIEDU). This manuscript is related to Angela Maria Brol master thesis titled "Biomarcadores proteicos em mulheres portadoras de fibromialgia submetidas à hidroterapia" submitted to Biological Science and Health Graduate Program from the Universidade do Oeste de Santa Catarina, Santa Catarina, Brazil.

Conflicts of Interest: The authors declare no conflict of interest. The funders had no role in the design of the study; in the collection, analyses, or interpretation of data; in the writing of the manuscript, or in the decision to publish the results

\section{REFERENCES}

1. Provenza JR, Pollak DF, Martinez JE, Paiva ES, Helfenstein M, Heymann R, et al. Fibromialgia. Rev Bras Reumatol. 2004; 44: 443-449.

2. Ablin J, Neumann L, Buskila D. Pathogenesis of Fibromyalgia: a review. Joint Bone Spine. 2008; 75: 273-279.

3. Pinto NS, Monteiro MOB, Paiva DN, Santos-Filho SD, Misssailidis S, Thompson D. Fibromyalgia and the relevance of the whole-body vibration exercises in vibratory platforms: a short review. Braz. Arch. Biol. Technol. 2012; 55: 6167.

4. Cavalcante AB, Sauer JF, Chalot SD, Assumpção A, Lage LV, Matsutani L, et al. A Prevalência de Fibromialgia: uma revisão de literatura. Rev Bras Reumatol. 2006; 46: 40-48.

5. Queiroz LP. Worldwide Epidemiology of Fibromyalgia. Curr Pain Headache Rep. 2013; 17: 356.

6. Wolfe F, Smythe HA, Yunus MB, Bennett RM, Bombardier C, Goldenberg DL, et al. The American College of Rheumatology 1990 Criteria for the Classification of Fibromyalgia: Report of the Multicenter Criteria Committee. Arthritis Rheum. 1990; 33: 160-172.

7. Atallah-haun M, Ferraz D, Pollak D. A validação dos critérios do Colégio Americano de Reumatologia para classificação de fibromialgia em uma população brasileira. Rev. Bras. Reumatol. 1999; 39: 221-30.

8. Fitzcharles M, Shir Y, Ablin JN, Buskila D, Amital H, Henningsen P, et al. Classification and Clinical Diagnosis of Fibromyalgia Syndrome: recommendations of recent evidence-based interdisciplinary guidelines. Evid Based Complement Alternat Med. 2013; 528952.

9. Heymann RE, Paiva ES, Helfenstein M, Pollak DF, Martinez EJ, Provenza JR, et al. Consenso Brasileiro do Tratamento de Fibromialgia. Rev Bras Reumatol. 2010; 50: 56-66.

10.Silva KMOM, Tucano SJP, Kumpel C, De Castro AAM, Porto EF. Efeito da Hidrocinesioterapia sobre a qualidade de vida, capacidade funcional e qualidade do sono em pacientes com fibromialgia. Rev. Bras. Reumatol. 2012; 52 : 846-857.

11.McVeigh JG, McGaughey $\mathrm{H}$, Hall M, Kane $P$. The effectiveness of hydrotherapy in the management of fibromyalgia syndrome: a systematic review. Rheumatol Int. 2008; 29: 119-130.

12.Langhorst J, Musial F, Klose P, Hauser, W. Efficacy of hydrotherapy in fibromyalgia syndrome - a meta-analysis of randomized controlled clinical trials. Rheumatol. 2009; 48: 1155-1159.

13. Hecker CD, Melo C, Tomazoni SS, Martins RABL, Leal Junior ECP. Análise dos Efeitos da Cinesioterapia e da Hidrocinesioterapia sobre a Qualidade de Vida de Pacientes com Fibromialgia: um ensaio clínico randomizado. Fisioter Mov. 2009; 24:57-64.

14.Barbosa EB, Vidotto A, Polachini GM, Henrique T, Trovó De Marqui AB, Tajara EH. Proteômica: metodologias e aplicações no estudo de doenças humanas. Rev Assoc Med Bras. 2012; 58: 366-375.

15.Bazzichi L, Ciregia F, Giusti L, Baldini C, Giannaccini G, Giacomelli C, et al. Detection of potential markers of primary fibromyalgia syndrome in human saliva. Proteomics Clin Appl. 2009; 3: 1296-1304. 
16. Bazzichi L, Da Valle Y, Rossi A, Giacomelli C, Sernissi F, Giannaccini G, et al. A Multidisciplinary Approach to Study the Effects of Balneotherapy and Mud-bath Therapy treatments on Fibromyalgia. Clin Exp Rheumatol. 2013; 31:111120.

17.Uçeyler N, Valenza R, Stock M, Schedel R, Sprotte G, Sommer C. Reduced levels of anti-inflammatory cytokines in patients with chronic widespread pain. Arthritis Rheum. 2006; 54: 2656-2664.

18.Toda, K. The Modification of the American College of Rheumatology Preliminary Diagnostic Criteria for Fibromyalgia Should Be Supplemented and Revised. J Rheumatol. 2011; 38: 2074.

19. Mciver KL, Evans C, Kraus RM, Ispas L, Sciotti VM, Hickner RC. NO-Mediated alterations in skeletal muscle nutritive blood flow and lactate metabolism in fibromyalgia. Pain. 2005; 120: 61-69.

20.Gerdle B, Soderberg K, Salvador Puigvert L, Rosendal L, Larsson B. Increased interstitial concentrations of pyruvate and lactate in the trapezius muscle of patients with fibromyalgia: a microdialysis study. J Rehabil Med. 2010; 42: 679-687.

21.Silva KMOM, Tucano SJP, Kumpel C, De Castro AAM, Porto EF. Efeito da Hidrocinesioterapia sobre a qualidade de vida, capacidade funcional e qualidade do sono em pacientes com fibromialgia. Rev Bras Reumatol. 2012; 52 : 846-857.

22. Marques, AP, Barsante S, Assumpção A, Matsutani LA, Lage LV, Pereira, CAB. Validação da Versão Brasileira do Fibromyalgia impact Questionnaire (FIQ). Rev Bras Reumatol. 2006; 46: 24-31.

23. Buskila, D. Fibromyalgia, chronic fatigue syndrome and myofascial pain syndrome. Curr Opin Rheumatol. 2011; 13: 113-123.

24.Buckle P. Ergonomics and Musculoskeletal disorders: overview. Occup Med. 2005; 55: 164-167.

25.Kaplan RM. Quality of Well Being in Patients with Fibromyalgia. J Rheumatol. 2000; 27: 785-789.

26. Neumann L. Measuring Health Status in Israeli Patients with Fibromyalgia Syndrome and Widespread pain and healthy individuals: utility of the SF-36. Semin Arthritis Rheum. 2000; 29: 400-408.

27. Wong DT. Salivary diagnostics powered by nanotechnologies, proteomics and genomics. J Am Dent Assoc. 2006; 137: 313-321

28. Akman HO, Oldfors A, DiMauro S. Glycogen Storage Diseases of Muscle. In: Darras BT, Jones HR, Ryan MM, De Vivo DC (2nd ed) Neuromuscular Disorders of Infancy, Childhood, and Adolescence. Academic Press; 2015, P. 735 760.

29. Dimauro SAF, Miranda AF, Khan KS, Gitlin K, Friedman R. Human Muscle Phosphoglycerate Mutase Deficiency: Newly Discovered Metabolic Myopathy. Sci. 1981; 12: 1277-1279.

30.Gladden LBA. Lactatic Perspective on Metabolism. Med Sci Sports Exerc. 2008; 40: 477-485.

31. Wallace DJ, Gavin IM, Karpenko O, Barkhordar F, Gillis BS. Cytokine and chemokine profiles in fibromyalgia, rheumatoid arthritis and systemic lupus erythematosus: a potentially useful tool in differential diagnosis. Rheumatol Int. 2015; 35: 991-996.

32. Wallace DJ. Is there a role for cytokine based therapies in fibromyalgia? Curr Pharm Des. 2006; 12: 17-22.

33.Sommer C, White F. Cytokines, Chemokines, and Pain. In: Beaulieu P, Lussier D, Porreca F, Dickenson A (1st ed) Pharmacology of Pain. Seattle: IASP Press; 2010. P. 279-302.

34.Docke WD, Asadullah K, Belbe G, Ebeling M, Höflich C, Friedrich M, et al. Comprehensive biomarker monitoring in cytokine therapy: heterogeneous, time-dependent, and persisting immune effects of interleukin-10 application in psoriasis. J Leukoc Biol. 2009; 85: 582-593.

(C) 2020 by the authors. Submitted for possible open access publication under the terms and conditions of the Creative Commons Attribution (CC BY NC) license (https://creativecommons.org/licenses/by-nc/4.0/). 